\title{
VALORIZACIÓN DE LA VIVIENDA Y DIFICULTAD PARA SU ACCESO EN EL MERCADO FORMAL DE ROSARIO
}

\author{
HOUSING VALORIZATION AND DIFFICULTY FOR ACCESS TO THE FORMAL MARKET \\ OF ROSARIO
}

\section{Cintia Ariana Barenboim ${ }^{1}$}

\section{Resumen}

Desde la post-convertibilidad y con la reactivación de la economía, la industria de la construcción creció, expandiéndose significativamente la oferta inmobiliaria en Rosario. Sin embargo, el mercado residencial estuvo orientado solo para quienes tenían capacidad de pago, obedeciendo a una lógica especulativa. Los bienes inmuebles se comportaron como un activo financiero produciendo grandes ganancias y un incremento revelador en el precio, dificultando el acceso a la vivienda.

El presente artículo tiene como objetivo evaluar el impacto de la valorización en las propiedades inmuebles particularmente para los sectores medios y medios-bajos. A partir de la comparación entre la evolución de los precios de viviendas tipo y la evolución de los ingresos medios se conocen los cambios del esfuerzo monetario. También se realiza un análisis de contenido de documentos escritos y entrevistas semi-estructuradas. Entre los resultados, se verifica que se ha reducido el poder de compra necesitando el doble de años ingresos medios (AIM), durante los años 2003 y 2016. Esto fue más acentuado en los departamentos, unidades elegidas como resguardo de capital, creciendo la demanda de alquiler. En conclusión la exclusión a la vivienda, contribuye cada vez más con la segmentación socioespacial, debiendo el Estado implementar estrategias para facilitar su acceso.

Palabras clave: valorización inmobiliaria, acceso a la vivienda, sectores medios y medios-bajos, poder de compra, demanda de alquiler.

\begin{abstract}
Since the post-convertibility and with the reactivation of the economy, the construction industry grew, significantly expanding the real estate offer in Rosario. However, the residential market was oriented only to those who had payment capacity, obeying a speculative logic. Real estate behaved like a financial asset producing big gains and a revealing increase in the price, making access difficult to the house.

The purpose of this article is to evaluate the impact of real estate valuation, particularly for the middle and low-middle sectors. From the comparison between the evolution of prices of standard houses and the evolution of average incomes, the changes in the monetary effort are known. A content analysis of written documents and semi-structured interviews is also carried out. Among the results, it is verified that purchasing power has been reduced, necessitating double the average annual income (AAl), during the years 2003 and 2016. This was more pronounced in the departments, units chosen as a capital reserve, increasing the rental

\footnotetext{
1 Posdoctorado en segregación socioespacial y valoración inmobiliaria (CURDIUR-UNR). Investigadora Asistente del CONICET. Docente Titular de Planeamiento y Urbanismo (FCEIA-UNR), Enfoques Socioantropológico del Habitar, Análisis del Mercado Inmobiliario y Estrategias de Inversión (FA-UAI). Directora y co-directora de trabajos de investigación radicados en el Centro de Alto Estudios Arquitectura (UAI), Secretaria de Ciencia y Técnica (UNR) y Lincoln Institute of Land Policy. E-mail: arq.barenboim@gmail.com
} 
demand. In conclusion, exclusion to housing contributes increasingly to socio-spatial segmentation, and the State must implement strategies to facilitate its access.

Keywords: real estate valuation, access to housing, middle and low-middle sectors, purchasing power, rental demand. 


\section{INTRODUCCIÓN}

El manejo del suelo urbano ${ }^{2}$ en Argentina presenta graves temáticas referidas a los altos precios (proceso de valorización acelerada más reciente), la convivencia e interrelación de los mercados formales e informales, la incapacidad del mercado formal para proveer tierra y vivienda a precios accesibles para todos los sectores de la población, los procesos de fragmentación espacial y de segregación residencial, vinculados a la existencia de grandes áreas sin servicios (Clichevsky, 2006; Smolka, 2005).

Cada lote en la ciudad soporta simultáneamente diversos tipos de utilidades: en primer término, la absoluta urbana que comparten todos los terrenos; en segundo lugar, una o dos primarias relacionadas con la localización e intensidad y finalmente, sostienen una de las secundarias vinculada al uso, siendo la más elevada la que se manifiesta en el mercado. La combinación de las rentas sobre cada lote conforma lo que se denomina la "renta total" y es esta categoría la que sirve de base en la conformación de los "precios del suelo urbano" (Jaramillo, 2010)

Particularmente, con la recuperación de la economía desde el año 2003, se produjo una inflación de los precios relativos de todos los bienes y servicios, siendo el precio promedio del suelo urbano uno de los aumentos más significativos. Al respecto, Baer menciona que:

“...el aumento del precio del suelo obedece al incremento de la competencia de la demanda derivada sobre la oferta física, jurídica y económica del suelo (aprovechada en alguna medida por los propietarios) y, en relación a ello, a la distribución territorial y al tipo de producto inmobiliario construido luego de la crisis" (Baer, 2011:300).

En Rosario, el precio de los terrenos e inmuebles reflejó esta lógica de articulación entre propietarios, demanda derivada, vinculada al tipo e intensidad de usos que se espera lograr, y demanda final, referida al consumo para el acceso propio a la vivienda. Esta última demanda está determinada, según Eckert (1990) por los niveles de empleo e ingreso, el poder adquisitivo, la disponibilidad de financiamiento, las tasas de interés, los costos de transacción y en consecuencia, los valores de la tierra urbana.

El incremento se ha verificado en todas las zonas de la ciudad, incluso en las menos requeridas, ensanchando aún más los contrastes de la valorización del suelo que existían y la posibilidad de acceso a los bienes inmuebles. La restricción de acceso a la propiedad, se

2 La CEPAL define al suelo urbano, según Herzer (2005), como una porción de tierra que ha sido convertida en urbana de acuerdo a las regulaciones vigentes en cada realidad, que posee infraestructura básica y ambiente natural adecuado, sin riesgos y cuyos ocupantes poseen seguridad en la tenencia para la ocupación y el uso del mismo (escritura pública u otro tipo de instrumento público jurídico). 
relaciona principalmente, con la depreciación del dólar, la inflación monetaria y la insuficiencia de propuestas de financiamiento para los sectores medios y medios-bajos a largo plazo. Cabe señalar que, a pesar de que en los últimos años se produjo una pérdida real de compra de la demanda final, el costo de los bienes inmuebles alcanza valores ampliamente superiores a los que se registraban antes de la crisis del 2001 cuando existía (en términos generales) un poder adquisitivo en dólares más elevado y mayor financiamiento.

La distribución del espacio residencial concurre de forma desigual, pudiéndose analizar mediante el comportamiento territorial de las solicitudes de construcción. Durante la primera década, entre los años 2004 y 2013 inclusive, se construyeron a razón de 5.800 viviendas por año, estando concentrada la construcción solamente en uno de los seis distritos de Rosario. Es decir que el Distrito Centro concentra el 55\% del total de las viviendas construidas, siendo además la zona más cara de la ciudad. Si bien en los últimos tres años se desacelera el ritmo de la construcción, el Distrito Centro continua siendo el de mayor importancia, absorbiendo el 47 \% de los permisos de edificación en el 2016 (Fundación Banco Municipal Rosario, 2016).

En este contexto, interesa explicar brevemente, la evolución del mercado inmobiliario en la ciudad de Rosario. Luego relevar los precios tanto de los terrenos como de las viviendas tipo (casa y departamento, ambos de dos dormitorios) para verificar su valorización inmobiliaria. Posteriormente, analizar el impacto de dicho encarecimiento comparando la evolución de los precios de una unidad tipo con la evolución del ingreso medio anual (AIM). EI estudio permitirá conocer las variaciones de la presión del consumo de un bien inmueble sobre la estructura de ingreso medio actual de los rosarinos.

\section{EVOLUCIÓN DEL MERCADO INMOBILIARIO}

A partir del 2003, Rosario experimentó un rápido crecimiento de la actividad económica motivada, principalmente, por la renta generada en el sector agropecuario. ${ }^{3}$ La falta de confianza en el sistema financiero, la devaluación de la moneda y las bajas tasas de interés, determinaron la inversión de estos beneficios extraordinarios en la industria de la construcción. En consecuencia, se registró una considerable mutación en los destinos de los fondos excedentes principalmente de las empresas y también de las familias. Los bienes inmuebles

\footnotetext{
${ }^{3}$ Rosario y su Aglomerado ocupan una posición estratégica como nexo entre la región agrícola pampeana y los mercados mundiales, así como entre diversas regiones del país; además contiene al complejo aceitero y al conjunto de puertos exportadores más importantes del país.
} 
comenzaron a comportarse como un activo financiero produciendo grandes ganancias y un incremento más que significativo en el precio de los inmuebles (Barenboim, 2010).

La reactivación del mercado inmobiliario junto con las nuevas normativas locales dieron lugar a grandes transformaciones edilicias en la ciudad. Por un lado, a través de la densificación vertical con los nuevos edificios y torres jardín en la tradicional área central y zona ribereña y por otro, un crecimiento horizontal (suburbanización) con los nuevos emprendimientos residenciales hacia la periferia y el área metropolitana.

Sin embargo, el "boom inmobiliario" no favoreció al conjunto de la sociedad. El aumento del valor en las propiedades dificulto el acceso a la vivienda propia de los sectores medios y medios-bajos, recurriendo generalmente al mercado de alquiler, y de los sectores bajos, que acudieron a la construcción de viviendas precarias en los asentamientos informales, cuando no eran absorbidos por los planes sociales del Estado.

Durante el año 2008, hubo un breve desaceleramiento en el crecimiento del sector de la construcción, como consecuencia del conflicto entre gobierno y sector agropecuario en torno al incremento de las retenciones a las exportaciones de granos, la sequía que afectó la producción agropecuaria y la amenaza de la crisis financiera mundial. No obstante, las retenciones no se establecieron y la crisis internacional no impactó, habiendo en el 2010 un crecimiento del PBI del 9,2\% en la provincia de Santa Fe (INDEC, 2010).

Desde mediados del año 2011 en adelante, al incremento constante de precios que venían sufriendo los bienes inmuebles, se suma el aceleramiento de la inflación de la economía incrementando aún más los mismos y marcando una preocupación general (constructora, comitente, inmobiliaria). Además, el cepo cambiario exigió la pesificación y/o corrección de precio en la comercialización, en virtud de la brecha entre el dólar oficial y el marginal o en su defecto dilatar su comercialización en el mercado. Las operaciones de inmuebles usados se contrajeron mientras que la de los emprendimientos desde pozo continuarón su curso.

A partir del relativo estancamiento del dólar y los rendimientos negativos de los plazos fijos con respecto a la inflación, la vivienda ya no solo era la cristalización de excedentes agropecuarios que no encontraban mejor uso sino era también una vía de las empresas y otros sectores sociales para escapar de la depreciación del peso, sin recurrir a la lógica del mercado financiero (Centro de Estudios Económico y Sociales Scalabrini Ortiz, 2016).

Recién en el año 2012 se lanzan dos créditos para la adquisición de la vivienda propia orientada a las clases medias y medias-bajas. Por un lado, a nivel nacional se implementa el Programa "Pro.Cre.Ar" que contaba con dos líneas básicas, una para aquellas personas que 
tienen un lote propio (construcción, ampliación y refacción) y otra para aquellas que no disponían de un terreno (compra de terreno y construcción, vivienda a estrenar y desarrollos urbanísticos). Por el otro lado, a nivel provincial y en menor escala, el Programa "Mi Tierra, Mi Casa" consistió en loteos sobre tierras oficiales, a precios inferiores a los de mercado. Este destinó además un cupo especial de terrenos para los que ya tenían un crédito Pro.Cre.Ar en Rosario. Ambos tuvieron una evolución favorable sin embargo no lograron absorber la totalidad de la demanda existente, e inclusive el Pro.Cre.Ar. sufrió en el último año modificaciones que limitaron su acceso.

Desde finales del 2015, con la liberación del régimen cambiario y la devaluación del dólar a un 60\% hubo una re-dolarización de mercado inmobiliario incrementando el precio de los departamentos en una proporción similar, alejando cada vez a más familias la posibilidad de adquirir la vivienda propia en Rosario.

\section{VALORIZACIÓN DE LOS BIENES INMUEBLES}

El valor del suelo y de los inmuebles fueron los incrementos más reveladores en Rosario, demostrando un proceso gradual y progresivo de exclusión en materia de acceso a la vivienda propia en el mercado formal.

Los factores más relevantes que inciden en dicho incremento se vinculan principalmente según Eckert (1990) con: el estado general de la economía (pesificación, inflación, niveles de ingreso, reducción de poder adquisitivo); el mercado inmobiliario (disponibilidad de financiamiento, relación entre la oferta y la demanda, costo de transacción, estrategias de marketing), las normativas urbanísticas locales (mayor densificación, cambios de usos), los aspectos sociales (deseo o prestigio por vivir en cierto barrio), los atributos físicos de lugar (tamaño, topografía y características lote) y localización de la parcela con respecto a otros lugares importantes de la ciudad.

Rosario presenta características heterogéneas, conviviendo allí situaciones que pueden identificarse sintéticamente a través de las distintas modalidades de ocupación y transformación en los barrios. Para el análisis de los precios de terrenos y de viviendas, se seleccionó la unidad tipo para una familia, que consta de una superficie de $70 \mathrm{~m}^{2}$, (casas y departamentos, ambos de dos dormitorios). Además, se obtuvo un promedio flotante aproximado de las áreas de valor intermedio de la ciudad (barrios Arroyito, Echesortu, Refinería, entre otros). 
Tabla 1. Comparación entre los precios promedios de terrenos e inmuebles de dos dormitorios en la ciudad de Rosario $\left(U \$ s / m^{2}\right)$. Período $2003-2016$.

\begin{tabular}{|c|c|c|c|}
\hline Año & Precio Promedio Terrenos (U\$s/m²) & Precio Promedio Casas (U\$s/m²) & $\begin{array}{c}\text { Precio } \\
\text { Promedio } \\
\text { Dptos. } \\
\left(\mathrm{U} \$ \mathrm{~s} / \mathrm{m}^{2}\right)\end{array}$ \\
\hline 2003 & 175 & 340 & 350 \\
\hline 2004 & 205 & 375 & 380 \\
\hline 2005 & 240 & 410 & 410 \\
\hline 2006 & 280 & 450 & 500 \\
\hline 2007 & 320 & 520 & 600 \\
\hline 2008 & 360 & 600 & 720 \\
\hline 2009 & 490 & 690 & 850 \\
\hline 2010 & 430 & 770 & 980 \\
\hline 2011 & 460 & 800 & 1100 \\
\hline 2012 & 500 & 880 & 1230 \\
\hline 2013 & 540 & 950 & 1320 \\
\hline 2014 & 565 & 1040 & 1440 \\
\hline 2015 & 595 & 1100 & 1580 \\
\hline 2016 & 620 & 1450 & 1900 \\
\hline Var 03-16 & $354 \%$ & $426 \%$ & $542 \%$ \\
\hline
\end{tabular}

Fuente: elaboración propia sobre entrevistas a agentes inmobiliarios y avisos del diario La Capital, 2003 a 2016.

Durante los últimos catorce años, los precios de los inmuebles y de los terrenos se han incrementado significativamente. Especialmente desde el año 2006 hasta la actualidad, el valor de los departamentos sobresalió en relación al de las casas, ascendiendo a 542\%. Esto confirma la preferencia en la elección de dichas unidades como un objeto de ahorro y de especulación, produciéndose para ser usados como un activo que resguarda el capital en lugar de pensarse para ser habitada. 
La valorización inmobiliaria promovida en la ciudad produce un déficit habitacional elevado. Al respecto, el Consejo Económico y Social (2010), expresa que hay 50.000 hogares que aún tienen necesidades de una nueva vivienda, y no pueden acceder a la misma, sea por habitar en edificaciones en malas condiciones o por hacinamiento. La mitad del total, se encuentra en los sectores asalariados de ingresos medios y medio-bajos mientras la otra en el segmento de menores recursos.

En contraste con este déficit habitacional, según datos del último Censo Nacional (2010), casi el 18,5 \% de las viviendas particulares del departamento Rosario están deshabitadas. Hay 434.977 viviendas en la ciudad, de las cuales 354.507 están ocupadas y 79.978 se encuentran vacías.

En suma el boom inmobiliario de Rosario no tuvo connotaciones positivas para toda la sociedad, se trató de un fenómeno en donde se construyeron viviendas para resguardo de capital, permaneciendo gran cantidad de ellas vacías. El rol de la vivienda cambio, pasando de tener una función social a un fin netamente financiero.

\section{ESFUERZO MONETARIO PARA LA COMPRA DE UNA VIVIENDA TIPO}

El impacto del proceso de valorización inmobiliaria, puede ser analizado comparando la evolución de los precios de algún tipo de propiedad con la evolución de cierto parámetro de ingreso. Esto permite conocer las variaciones de la presión del consumo de un bien inmueble sobre la estructura de ingreso de las personas. En el caso del mercado residencial, Valiño expresa que:

“... uno de los indicadores más utilizados por su sencillez es el que pone en relación el precio de la vivienda y el ingreso salarial, aproximado por el coste medio salarial, y se corresponde más directamente con el concepto de accesibilidad o cuantos años de sueldo hay que ahorrar para pagar la vivienda" (Valiño, 2006: 12).

Otra manera, de establecer los cambios de esfuerzo monetario, es comparando la evolución de la porción del ingreso que debe ser destinado al consumo de un bien inmueble a través del alquiler. A diferencia del caso anterior aquí solo se destina una fracción del ingreso medio.

En suma, ambos indicadores apuntan a mercados de bienes inmuebles con características espaciales y contenidos sociales diferenciados; en consecuencia, requieren diferentes formas de acceso a la propiedad. 
En el mercado residencial, las unidades de comparación que se seleccionan, para establecer el esfuerzo monetario, es el prototipo habitacional más requerido para los sectores medios y medios-bajos en la ciudad de Rosario. Este corresponde a una vivienda unifamiliar o departamento usados (en buen estado) con una superficie cubierta promedio de $70 \mathrm{~m}^{2}$, constando de dos dormitorios, cocina, living-comedor y un baño. Cabe señalar además, que cuentan con superficies abiertas (patio o balcón) de aproximadamente $15 \mathrm{~m}^{2}$.

Para estimar la restricción de compra, si se toma el primer caso, se analiza el precio promedio de una casa/departamento tipo y se divide por la cantidad de salarios medios anuales, durante el período de estudio. Esto da cuenta de la cantidad de años de ingresos medios (AIM) necesarios para adquirir la vivienda tipo considerando el total del salario medio, significando de que hacerlo supondría la privación absolutamente de todas sus necesidades y consumos.

En Rosario, para el año 2003 se necesitaba un promedio de 5,6 AIM para comprar una casa tipo mientras que en el 2016 se requerían 8,8 AIM para el mismo propósito. Es decir, que se precisan ahorrar 3,2 años de salario medio más para comprar la misma unidad. En relación a un departamento tipo el incremento fue más acentuado. Al inicio del período se requería un promedio de 5,8 AIM incrementándose para el final a 11,5 AIM; prácticamente el doble que antes, se debe ahorrar 5,7 años más de salario medio (ver Tabla 2).

Tabla 2. Años de ingresos medios para acceder a una vivienda usada de dos dormitorios $\left(70 \mathrm{~m}^{2}\right)$ en la ciudad de Rosario. Período $2003-2016$.

\begin{tabular}{|c|c|c|c|c|c|}
\hline Años & $\begin{array}{c}\text { Precio Promedio } \\
\text { Casas }\end{array}$ & $\begin{array}{c}\text { Precio Promedio } \\
\text { Dptos. }\end{array}$ & $\begin{array}{c}\text { Ingreso Medio } \\
\text { Anual }\end{array}$ & $\begin{array}{c}\text { AIM } \\
\text { Casas }\end{array}$ & $\begin{array}{c}\text { AIM } \\
\text { Dptos. }\end{array}$ \\
\hline 2003 & 23800 & 24500 & 4.200 & 5,6 & 5,8 \\
\hline 2004 & 26250 & 26600 & 4.500 & 5,8 & 5,9 \\
\hline 2005 & 28700 & 28700 & 4.850 & 5,9 & 5,9 \\
\hline 2006 & 31500 & 35000 & 5.100 & 6,1 & 6,8 \\
\hline 2007 & 36400 & 42000 & 6.600 & 5,5 & 6,3 \\
\hline 2008 & 42000 & 50400 & 7.080 & 5,9 & 7,1 \\
\hline 2009 & 48300 & 59500 & 7.580 & 6,3 & 7,8 \\
\hline
\end{tabular}




\begin{tabular}{|c|c|c|c|c|c|}
\hline 2010 & 53900 & 68600 & 7.900 & 6,8 & 8,6 \\
\hline 2011 & 56000 & 77000 & 8.150 & 6,8 & 9,4 \\
\hline 2012 & 61600 & 86100 & 8.600 & 7,1 & 10,0 \\
\hline 2013 & 66500 & 92400 & 8.800 & 7,5 & 10,5 \\
\hline 2014 & 72800 & 100800 & 9.300 & 7,8 & 10,8 \\
\hline 2015 & 80000 & 110600 & 10.800 & 7,4 & 10,2 \\
\hline 2016 & 101500 & 133000 & 11.500 & 8,8 & 11,5 \\
\hline Promedio & 52.089 & 66.800 & 7.497 & 7 & 8 \\
\hline
\end{tabular}

Fuente: elaboración propia sobre avisos del diario La Capital, para precios de viviendas y sobre Reporte Inmobiliario para ingreso medio en la ciudad de Rosario, 2003 - 2016.

Ahora bien si se considera el segundo caso se toma solo una fracción del salario medio, Sánchez (2015) estima que se puede llegar a destinar hasta el 38\% para pagar un alquiler o un crédito hipotecario. Aquí la cantidad de años de ingresos medios necesarios para adquirir la vivienda tipo se acentúa aún más.

Cabe señalar que en la mayoría de los casos ese porcentaje se destina para el alquiler dado que acceder a un crédito hipotecario es muy complejo. Al respecto Rovitti dice que:

\begin{abstract}
“... las tasas que cobran los bancos están alrededor del $40 \%$ anual, el tiempo máximo para cancelar el monto otorgado no supera los 10 años, no otorgan el $100 \%$ de lo que se necesita para comprar el inmueble sino un $70 \%$ de la tasación que hace el mismo banco, que en la realidad es un $50 \%$ del valor de mercado y además es muy difícil calificar porque se necesita abultados sueldos en el núcleo familiar" (Rovitti, 2014:33).
\end{abstract}

Para el año 2003, se necesitaría un promedio de 14,9 AIM para comprar una casa tipo y 15,4 AIM para un departamento en Rosario mientras que en el 2016 se requerían 23,2 AIM y 30,4 AIM respectivamente para el mismo propósito. Es decir que se necesitan ahorrar prácticamente el doble del salario medio hacia final del período de estudio (ver Tabla 3).

Tabla 3. Fracción de años de ingresos medios para acceder a una vivienda usada de dos dormitorios $\left(70 \mathrm{~m}^{2}\right.$ ) en la ciudad de Rosario. Período $2003-2016$.

\begin{tabular}{|c|c|c|c|c|c|}
\hline Años & $\begin{array}{c}\text { Precio Promedio } \\
\text { Viviendas }\end{array}$ & $\begin{array}{c}\text { Precio Promedio } \\
\text { Dptos }\end{array}$ & $\begin{array}{c}\text { Ingreso Medio } \\
\text { Anual (38\%) }\end{array}$ & $\begin{array}{l}\text { AlM } \\
\text { Casas }\end{array}$ & $\begin{array}{l}\text { AlM } \\
\text { Dptos. }\end{array}$ \\
\hline
\end{tabular}




\begin{tabular}{|c|c|c|c|c|c|}
\hline 2003 & 23800 & 24500 & 1.596 & 14,9 & 15,4 \\
\hline 2004 & 26250 & 26600 & 1.710 & 15,4 & 15,6 \\
\hline 2005 & 28700 & 28700 & 1.843 & 15,6 & 15,6 \\
\hline 2006 & 31500 & 35000 & 1.938 & 16,3 & 18,1 \\
\hline 2007 & 36400 & 42000 & 2.508 & 14,5 & 16,7 \\
\hline 2008 & 42000 & 50400 & 2.690 & 15,6 & 18,7 \\
\hline 2009 & 48300 & 59500 & 2.880 & 16,8 & 20,7 \\
\hline 2010 & 53900 & 68600 & 3.002 & 18,0 & 22,9 \\
\hline 2011 & 56000 & 77000 & 3.097 & 18,1 & 24,9 \\
\hline 2012 & 61600 & 86100 & 3.268 & 18,8 & 26,3 \\
\hline 2013 & 66500 & 92400 & 3.344 & 19,9 & 27,6 \\
\hline 2014 & 72800 & 100800 & 3.534 & 20,6 & 28,5 \\
\hline 2015 & 80000 & 110600 & 4.104 & 19,5 & 26,9 \\
\hline 2016 & 101500 & 133000 & 4.370 & 23,2 & 30,4 \\
\hline Promedio & 52.089 & 66.800 & 2.849 & 17,65 & 22,0 \\
\hline
\end{tabular}

Fuente: elaboración propia sobre avisos del diario La Capital, para precios de viviendas y sobre Reporte Inmobiliario para ingreso medio en la ciudad de Rosario, 2003 - 2016.

Cabe señalar que esta brecha se agranda al aumentar la condición socioeconómica de los barrios. La variación absoluta de AIM necesarios para comprar una vivienda de similares características es más significativa en el centro que en los barrios de Rosario, puesto que la valorización inmobiliaria es mayor. El acceso a la tierra y a la vivienda para los sectores medios y medio-bajos resulta muy acotado en nuestra ciudad. Al respecto Doncel ${ }^{4}$ expresa que:

\begin{abstract}
"Rosario no ofrece la posibilidad de adquirir un terreno, dentro de un sector medio-bajo. Lo que nos gobiernan son los responsables de que la gente este alquilando o, en el peor de los casos, en villas de emergencia. El costo de la tierra rural es tan solo de 10 U\$s. Se podrían integrar barrios, entregándole a cada rosarino (necesitado) un lote de $150 \mathrm{~m}^{2}$, dotándolos de agua, alumbrado, calles y entregándoles las escrituras. La
\end{abstract}

${ }^{4}$ EI CPN. Jorge Doncel es desarrollador de grandes urbanizaciones (los barrios cerrados y abiertos de Aldea, Parque Habitacional Ludueña, la urbanización mixta de Newbery y Parque Empresarial Rosario) y asesor de funcionarios públicos, particularmente de convenios urbanísticos, en Planeamiento de la Municipalidad Rosario. 
persona va a vivir más integrado a la ciudad que en una villa de emergencia. Sin embargo, las normativas para las Zonas IV, dicen no urbanizable, requieren lotes de grandes dimensiones, resultando el costo final tanto que no se logra hacer nada para los sectores de la población más limitados y se orienta a la clase alta. En ese sentido el Municipio pone normas a una parte de la ciudad, orienta solo el mercado formal y para el informal no hay normas, están fueran del sistema. Hoy en Rosario sobra tierra, capacidad de trabajo, gente con voluntad, entre otras cuestiones". 5

Es por ello, que ante un atraso salarial en dólares tan significativo y la falta de un sistema financiero hasta el año 2012, los promotores inmobiliarios orientaron sus desarrollos hacia los sectores de ingresos altos y medios-altos. Estos son los estratos sociales que no dependen del ingreso mensual, ni tampoco de un crédito hipotecario para comprar una vivienda (Barenboim, 2014: 118).

\section{DISPUTA ENTRE LA RENTA INMOBILIARIA Y EL ALQUILER}

En los últimos años, el incremento de alquiler de inmuebles no fue el resultado del mejoramiento de sus condiciones contractuales, del aumento de la oferta de las unidades locativas, ni de la existencia de bajos costos de arrendamiento. La expansión de esta modalidad, se vincula con los altos costos del suelo, los incrementos de valores de la construcción, el retroceso del salario con respecto al valor de las propiedades y la falta de financiamiento adecuado para las familias de estratos socioeconómicos medios y medio-bajos (Barenboim, 2014).

El Instituto Nacional de Estadística y Censos de la República Argentina (INDEC) para el año 2001, cuando en Rosario había 902.080 habitantes, estima que la ciudad tenía un 67,3 \% de propietarios y un 19,9 \% de inquilinos, mientras que en el 2010 había 948.312 habitantes, con un 58,3 \% de propietarios y un 28,2 \% de inquilinos. Desde la Cámara de Empresas Inmobiliarias de Rosario (CADEIROS), Rovitti consideró que hoy ascendió al 30 \%:

“... hay más de 300.000 personas que alquilan, por inmobiliaria están pasando cerca de 95.000 contratos de alquiler, por lo tanto, también está latente la necesidad de tener un primer techo en la clase media y en consecuencia estamos buscando alternativas de financiamiento también para esa gente que no cuenta con políticas de Estado, que son las que trascienden a los gobiernos y que deben planificarse a largo plazo" (Rovitti, 2014:32).

El mercado de compra-venta ha registrado un aumento general de precios en el mercado de alquiler, en mayor medida en las áreas centrales y en menor grado en la

\footnotetext{
${ }^{5}$ Entrevista realizada a la CPN. Jorge Doncel. Rosario, 17/05/12.
} 
periferia. Esto se debe al aumento de la oferta de unidades locativas y a la elevada inflación de precios ${ }^{6}$.

Durante los años 2003 y 2016, los montos se cuadriplicaron en las distintas propiedades. Asimismo, dicho incremento de valores se acentuó más en las casas que en los departamentos tipo, aproximadamente un $22 \%$. Al respecto, Martinucci ${ }^{7}$ expresa que: “... hay una demanda insatisfecha de alquiler de casas dado que no son pensadas como inversión sino como lugar donde vivir". ${ }^{8}$ Es decir que tienen un valor de uso y no de cambio. Asimismo Doncel estima que de las unidades ofertadas: “... cuatro de cada cinco casas son las que se venden y una se alquila."

Tabla 4. Incremento general de precios promedios en el mercado de alquiler en la ciudad de Rosario (U\$s). Período 2003 - 2016.

\begin{tabular}{|c|c|c|}
\hline \multirow{2}{*}{ Años } & \multicolumn{2}{|c|}{ Viviendas tipo $\left(70 \mathrm{~m}^{2}\right)$} \\
\cline { 2 - 3 } & Casas & Dptos. \\
\hline 2003 & 125 & 105 \\
\hline 2004 & 150 & 120 \\
\hline 2005 & 180 & 150 \\
\hline 2006 & 210 & 170 \\
\hline 2007 & 240 & 200 \\
\hline 2008 & 280 & 240 \\
\hline 2009 & 320 & 270 \\
\hline 2010 & 360 & 310 \\
\hline 2011 & 400 & 345 \\
\hline 2012 & 440 & 390 \\
\hline 2013 & 475 & 430 \\
\hline
\end{tabular}

\footnotetext{
${ }^{6}$ Para evitar el incremento de los alquileres, en algunos casos, los inquilinos recurren al pago por adelantado, resultando dicha ecuación conveniente para ambas partes, sobre todo para conocer con precisión la relación cambiaria en el momento de la operación.

${ }^{7}$ El contador público Daniel Martinucci es titular de GAMA Inmobiliaria y miembro de las Comisiones Directivas de la Cámara de Empresas Inmobiliarias de Rosario (CADEIROS) y de la Federación Inmobiliaria de la República Argentina (FIRA).

${ }^{8}$ Entrevista realizada a CPN Daniel Martinucci. Rosario, 03/03/17.

9 Ídem 3.
} 


\begin{tabular}{|c|c|c|}
\hline 2014 & 500 & 470 \\
\hline 2015 & 530 & 500 \\
\hline 2016 & 490 & 450 \\
\hline Promedio & 336 & 296 \\
\hline Var 03 - 16 & $392 \%$ & $428 \%$ \\
\hline
\end{tabular}

Fuente: elaboración propia sobre avisos clasificados del diario La Capital y Revista Mercado inmobiliario de Rosario, abril 2003 a 2016.

A su vez, el Centro de Estudios Económico y Sociales Scalabrini Ortiz (2016) menciona que el precio de los alquileres aumento por debajo del precio de venta del inmueble. La razón de este fenómeno se desprende que el alquiler es fijado en base una puja entre el inquilino y el propietario, lo que obliga que la evolución de su valor ronde entre los valores de aumento salarial y la inflación.

En Rosario se observa que las casas cuadriplicaron su valor y los departamentos se quintuplicaron (426\% y $542 \%$ respectivamente), mientras que los alquileres apenas cuadriplicaron su precio (casas $392 \%$ y departamentos $428 \%$ ). Estos datos refuerzan lo antedicho.

En el mercado residencial cuando el motivo de la compra es el de inversión, el objetivo es la rentabilidad periódica que puede obtenerse mediante su arrendamiento. La decisión sobre en que conviene colocar el inmueble, en venta o en alquiler, depende del flujo de renta esperada. Al respecto, Baer explica que:

"El principal parámetro consiste en los valores de rentabilidad que surgen al dividir el precio estimado de venta por el monto anual de renta que se podría obtener con el alquiler de la propiedad. Esta ecuación entre valor de venta y costo de alquiler refiere a la renta bruta de la propiedad inmobiliaria y constituye un indicador útil para analizar la inversión inmobiliaria y la evolución del mercado de alquileres" (Baer, 2011: 318).

La oferta de alquileres se ha ampliado a partir del mejoramiento de la rentabilidad inmobiliaria en Rosario. La renta bruta de alquiler resulta más conveniente que otras opciones de inversión, empezando por las tasas reales que ofrecen los plazos fijos en los bancos. Martinucci agrega que: “...actualmente la inflación incide también en esa elección, por más que las tasas de los plazos fijos sean altas nunca van a ser iguales que la inflación. En cambio las propiedades si se valorizan a la par de la inflación, manteniendo su valor en el tiempo". ${ }^{10}$

10 Ídem 7. 
La rentabilidad promedio anual de la inversión inmobiliaria volcada en estas unidades habitacionales oscila entre el 4,5 a $6 \%$, mientras que un plazo fijo es de un 2,5\% aproximadamente, dependiendo del banco y del momento en que se otorgue. Martinucci expresa que: “... el gran enemigo de la inversión inmobiliaria es la especulación financiera. Hay una relación inversa entre intereses e inversión inmobiliaria, a mayores intereses menor inversión en la construcción y viceversa". ${ }^{11}$

Del mismo modo generalmente es más conveniente que invertir en la compra de dólares, dependiendo de su cotización. En los primeros años en Rosario estaban muy desvalorizadas las propiedades y por más que aumentaban en dólares se continuaban vendiendo pero en los últimos años se redujo notablemente. Es decir que cuando las propiedades aumentan en dólares la demanda es menor y cuando se mantienen es mayor.

En síntesis, un mercado ideal para la inversión inmobiliaria asegura Martinucci: “... es cuando hay un dólar estable y tasas de interés bajas en plazos fijos a largo plazo" ${ }^{12}$ El estímulo económico de la inversión inmobiliaria no se debe solamente al recupero del capital sino también a la valorización de los activos a un ritmo extraordinario.

\section{CONCLUSIONES}

En la actualidad, hay una gran distorsión entre la noción de la vivienda como un "bien económico" y la necesidad de la vivienda con un fin social como un "lugar donde vivir". Esta unidad se produce como una mercancía más del mercado, siendo generalmente utilizada para inversión o resguardo del capital.

Es por ello que el mercado privado de vivienda rosarino construyó durante los últimos años solamente para quienes poseían garantías y capacidad de pago, obedeciendo exclusivamente a una lógica especulativa. Esto genera una situación de escasez relativa de unidades para vivir y una demanda extra en el mercado de unidades para inversión/resguardo. Lo antedicho sumado a la inflación monetaria, la falta de financiamiento adecuado y sostenido en el tiempo, entre otros factores, encarecieron a las propiedades por encima de las posibilidades de gran parte de la población.

Desde el año 2003 al presente, el poder de compra se ha limitado en los sectores medios y medios-bajos, para el caso de la vivienda tipo en la ciudad de Rosario. Esta reducción

\footnotetext{
11 Ídem 7.

12 Ídem 7.
} 
se ve más acentuada en la adquisición de los departamentos que en las casas, dado que son las unidades elegidas para la comercialización.

En consecuencia la polarización socioespacial se acentuó debiendo recurrir por un lado, los sectores medios y medios-bajos al mercado de alquiler local o a la compra de viviendas en la periferia, y por el otro, los sectores bajos, que no fueron absorbidos en los planes sociales, a la autoconstrucción de viviendas precarias en los asentamientos informales.

De acuerdo a la renta que se disponga se podrá acceder a un tipo de vivienda determinado, fragmentándose cada vez más socioeconómicamente el espacio en la ciudad. El boom inmobiliario local no tuvo connotaciones equivalentes para toda la sociedad, resultando difícil cumplir con el derecho a la vivienda propia.

En este sentido, el Estado (en todos sus niveles) debería dar respuesta a dicho fenómeno y acercar aún más a través de distintas estrategias a los constructores privados a la demanda existente y real de precios. El "financiamiento adecuado" a largo plazo es el elemento clave para el acceso a la vivienda, siendo el verdadero desafío reducir la cantidad de inquilinos o personas viviendo en condiciones precarias y aumentar la de propietarios en la ciudad de Rosario.

\section{BIBLIOGRAFÍA}

BAER, Luis. El mercado de suelo formal de la ciudad de Buenos Aires en su contexto metropolitano. Dinámica de precios de terrenos, desarrollo inmobiliario y acceso a la vivienda en la década de dos mil. Tesis de doctorado en Geografía. Buenos Aires: Facultad de Filosofía y Letras UBA, 2011.

BARENBOIM, Cintia Ariana. Dinámica inmobiliaria en la ciudad de Rosario. Período 1998 - 2009 en Revista Proyección, Mendoza, Nº 8 (4), p. 1 - 25, 2010.

BARENBOIM, Cintia Ariana. Mercado inmobiliario, normativa e impacto territorial: Rosario y su periferia. Rosario: Editorial UNR, 2014.

CENTRO DE ESTUDIOS ECONÓMICO Y SOCIALES SCALABRINI ORTIZ. Situación del mercado viviendas Rosario. CESO: Santa Fe, 2016.

CLICHEVSKY, Nora. Mercado de Tierras Urbano en la Argentina. Estados Unidos: The World BankBIRF, 2006.

CONSEJO ECONÓMICO Y SOCIAL. Actas de reunión Comisión Hábitat y Asentamientos Irregulares. Rosario: Municipalidad de Rosario, 2010. 
ECKERT, Joseph. Capítulo 7: Valuación de la tierra en Tasación de la propiedad y administración de la evaluación. Chicago: Asociación Internacional de Oficiales de la Evaluación, 1990.

FUNDACIÓN BANCO MUNICIPAL ROSARIO. Actividad Económica construcción. Rosario: Municipalidad de Rosario, 2016.2 Disponible en: www. fundacionbmr.org.ar/rosariodata/data.php?indicador $=1$ \&etiqueta $=80$ HERZER, Hilda. Renovación y cambio en el sur de la Ciudad de Buenos Aires. Buenos Aires: Instituto de Investigaciones Gino Germani de la UBA, 2008.

INSTITUTO NACIONAL DE ESTADÍSTICA Y CENSOS DE LA REPÚBLICA ARGENTINA (INDEC). Censo Nacional de Población, Hogares y Vivienda 2001 y 2010. Ministerio de Económica: Buenos Aires, 2014.

JARAMILLO, Samuel. Hacia una teoría de la renta de suelo urbano. Centro de Estudios sobre Desarrollo Económicos. Bogotá: Ediciones Uniandes, 2010.

ROVITTI, Carlos. Palabras del especialista de Cámara de Empresas Inmobiliarias de Rosario en CONSEJO ECONÓMICO Y SOCIAL. Hábitat y asentamientos irregulares en Rosario. Reflexiones colectivas para la construcción de políticas públicas. Rosario: Municipalidad de Rosario, 2014.

SÁNCHEZ, Nora. El problema del acceso a la vivienda. Se puede llegar a usar hasta el $38 \%$ del sueldo para pagar un alquiler en Clarín Ciudades. Buenos Aires: Clarín, 2015.

SMOLKA, Martim. El funcionamiento de los mercados del suelo en América Latina en BASUALDO, José Luis. Manejo de suelo urbano. Posibilidades y desafíos en el desarrollo de la ciudad de Corrientes. Corrientes: Instituto de Vivienda de Corrientes, 2005.

VALIÑO, Aurelia. Vivienda y familia. Medidas del esfuerzo y accesibilidad en rentas equivalentes según la Comunidad Autónoma de Residencia. Encuentro de Económica Pública. Almería: Universidad Complutense de Madrid, 2006.

Trabalho enviado em 11 de março de 2017.

Aceito em 26 de março de 2017. 